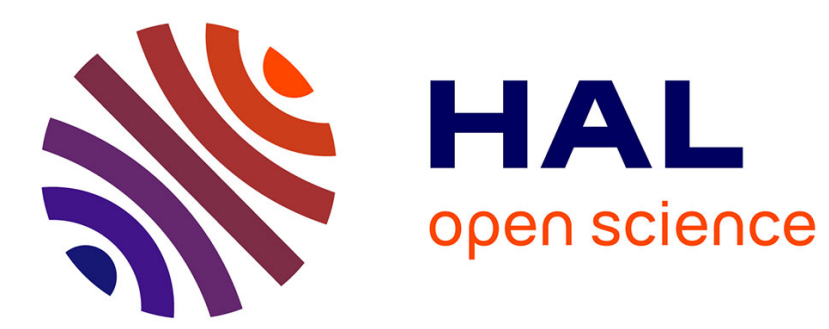

\title{
Répertoire des textes législatifs et réglementaires publiés pendant les mois de novembre 1997 à février 1998
}

- [.]revue Forestière Française, Rédaction

\section{To cite this version:}

- [.]revue Forestière Française, Rédaction. Répertoire des textes législatifs et réglementaires publiés pendant les mois de novembre 1997 à février 1998. 1998, pp.92-93. 10.4267/2042/5518 . hal03534998

\section{HAL Id: hal-03534998 \\ https://hal.science/hal-03534998}

Submitted on 19 Jan 2022

HAL is a multi-disciplinary open access archive for the deposit and dissemination of scientific research documents, whether they are published or not. The documents may come from teaching and research institutions in France or abroad, or from public or private research centers.
L'archive ouverte pluridisciplinaire HAL, est destinée au dépôt et à la diffusion de documents scientifiques de niveau recherche, publiés ou non, émanant des établissements d'enseignement et de recherche français ou étrangers, des laboratoires publics ou privés. 


\section{législation et \\ jurisprudence}

\section{RÉPERTOIRE DES TEXTES LÉGISLATIFS ET RÉGLEMENTAIRES PUBLIÉS PENDANT LES MOIS DE NOVEMBRE 1997 À FÉVRIER 1998}

\section{CODE FORESTIER - CODE RURAL}

\section{- Décrets}

Décret $n^{\circ}$ 97-1163 du 17 décembre 1997 modifiant le Code forestier et portant déconcentration des décisions relatives aux aménagements des forêts, aux défrichements de forêts incendiées et aux transactions en matière d'infractions à la législation sur le défrichement.

(J.O. Lois et Décrets, $n^{\circ} 296$ du 21 décembre 1997, pp. 18572-18574)

Décret $n^{\circ}$ 97-1236 du 26 décembre 1997 relatif à la tutelle de l'État sur l'Office national des Forêts et modifiant le Code forestier.

(J.O. Lois et Décrets, $\mathrm{n}^{\circ} 301$ du 28 décembre 1997, pp. 19050-19051)

\section{FONDS FORESTIER NATIONAL - REBOISE- MENT - PLANTS FORESTIERS}

\section{- Décret}

Décret du 27 janvier 1998 portant nomination au comité de contrôle du Fonds forestier national.
(J.O. Lois et Décrets, $n^{\circ} 28$ du 3 février 1998, p. 1718)

\section{- Arrêtés}

Arrêté du 23 décembre 1997 portant inscription de peuplements forestiers au registre des peuplements porte-graine classés.

(J.O. Lois et Décrets, $n^{\circ} 6$ du 8 janvier 1998, p. 361)

Concerne le Pin maritime des Landes de Gascogne.

La liste est consultable à la $\operatorname{DERF}(19$, avenue du Maine - 75732 PARIS CEDEX 15) ou au CEMAGREF (Domaine des Barres - 45290 NOGENT-SURVERNISSON).

Arrêté du 21 janvier 1998 portant fixation d'une région de provenance relative au Pin maritime.

(J.O. Lois et Décrets, $n^{\circ} 31$ du 6 février 1998, p. 1923)

La région 04-Landes Médoc est renommée 04-SudOuest Vergers. 


\section{ENSEIGNEMENT FORESTIER}

\section{- Décret}

Décret $n^{\circ}$ 98-60 du 27 janvier 1998 portant abrogation du décret $n^{\circ}$ 66-44 du 5 janvier 1966 érigeant un établissement d'enseignement agricole en établissement public doté de l'autonomie financière.

(J.O. Lois et décrets, $\mathrm{n}^{\circ} 28$ du 3 février 1998, p. 1712)

Transfert des bien meubles de I'ENITEF à l'ENGREF. Fermeture administrative de l'ENITEF.

\section{ENVIRONNEMENT}

\section{- Décrets}

Décret $n^{\circ}$ 97-1329 du 30 décembre 1997 portant création de la réserve naturelle de l'estuaire de la Seine.

(J.O. Lois et Décrets, $\mathrm{n}^{\circ} 1 \mathrm{du} 1^{\mathrm{er}}$ janvier 1998 , pp. 48-51)
Décret $n^{\circ}$ 98-38 du 16 janvier 1998 portant classement du Parc naturel régional du Perche (Basse Normandie et Centre).

(J.O. Lois et Décrets, n 15 du 18 janvier 1998, pp. 818-819)

\section{- Arrêté}

Arrêté du 29 octobre 1997 relatif à la liste des espèces végétales protégées en région Languedoc-Roussillon.

(J.O. Lois et Décrets, $n^{\circ} 13$ du 16 janvier 1998, pp. 674-675)

\section{ORGANISATION ADMINISTRATIVE}

\section{- Décret}

Décret $n^{\circ}$ 97-1235 du 26 décembre 1997 portant création et organisation de l'Institut national d'Horticulture.

(J.O. Lois et Décrets, $\mathrm{n}^{\circ} 301 \mathrm{du}$ 28 décembre 1997, pp. 19046-19050) 